\title{
The characteristics of fermented purple sweet potato (Ipomoea batatas) and black rice (Oryza sativa) using UV-irradiated Monascus purpureus
}

\author{
ISWIYANTI NOVITA ${ }^{1,2}$, OEDJIJONO $^{1}$, ARI ASNANI ${ }^{3, \bullet}$ \\ ${ }^{1}$ Department of Biology, Faculty of Biology, Universitas Jenderal Soedirman. J1. Dr. Suparno No. 63, Purwokerto Utara, Banyumas 53122, Central Java, \\ Indonesia. \\ ${ }^{2}$ Department of Health Analysis, Politeknik Kesehatan Kementerian Kesehatan Banjarmasin. Jl. H.M Cokrokusumo No. 1A, Sei Besar, \\ Banjarbaru 70714, South Kalimantan, Indonesia \\ ${ }^{3}$ Department of Chemistry, Faculty of Mathematic and Natural Sciences, Universitas Jenderal Soedirman, J1. Dr. Soeparno No. 61, Purwokerto Utara, \\ Banyumas 53122, Central Java, Indonesia, Tel.: +62-281-638793, Fax.: +62-281-638793, `email: ari.asnani@unsoed.ac.id
}

Manuscript received: 2 December 2020. Revision accepted: 11 January 2021.

\begin{abstract}
Novita I, Oedjijono, Asnani A. 2021. The characteristics of fermented purple sweet potato (Ipomoea batatas) and black rice (Oryza sativa) using UV-irradiated Monascus purpureus. Biodiversitas 22: 684-690. This research aimed to produce Monascus fermented product (MFP) with purple sweet potato (Ipomoea batatas (L.) Lam.) and black rice (Oryza sativa L.) using UV-irradiated Monascus purpureus Went and evaluated the characteristic of its antibacterial activity against Salmonella typhi. M. purpureus was irradiated with UV at $\lambda 254 \mathrm{~nm}$ for $0,2,3$, and $4 \mathrm{~min}$. The solid-state fermentation process was carried out for 7, 14, and 21 days. The pigments were measured at $\lambda 390 \mathrm{~nm}$ for yellow and $\lambda 500 \mathrm{~nm}$ for red. The ethanol extracts of MFP were analyzed for their antibacterial activity against $S$. typhi using the Kirby-Bauer method. The results showed that the highest yield of MFP was obtained from MFP-black rice $(51.88 \%$ ) that used UV-irradiated $M$. purpureus for $2 \mathrm{~min}$ and fermentation for 21 days. The highest absorbance value of MFPpurple sweet potato was obtained from UV-irradiated M. purpureus for $3 \mathrm{~min}$, whereas the highest absorbance value of MFP-black rice was obtained with UV-irradiated M. purpureus for $2 \mathrm{~min}$. Ethanol extracts of both MFP3-purple sweet potato and MFP2-black rice showed antibacterial activities against $S$. typh $i$ with minimum inhibitory concentration values of 0.2 and $0.15 \mathrm{~g} / \mathrm{mL}$, respectively. Thinlayer chromatography analysis of the ethanol extract from MFP2-black rice revealed the presence of bioactive saponin and flavonoid. These findings suggest that UV-irradiated $M$. purpureus was able to use both purple sweet potato and black rice substrates to produce MFP with antibacterial activity against S. typhi.
\end{abstract}

Keywords: Black rice, fermentation, Monascus, purple sweet potato, UV-irradiated

\section{INTRODUCTION}

Monascus purpureus Went is a filamentous fungus with known potential for natural pigment production through submerged or solid-state fermentation (Christiana 2016). During fermentation, M. purpureus will utilize starchy substrates and produce secondary metabolites in the form of pigments. Based on the color, Monascus pigments are classified into three categories, including red (monascorubramin and rubropunctamin), yellow (monascin and ankaflavin), and orange (monascorubrin and rubropunctatin) (Kim and Ku 2018). These pigments are widely used in the Asian region as a natural food colorant and as health products because of their bioactivities (Srianta et al. 2014).

Production of Monascus fermented product (MFP) is affected by the type of nutrients as well as physicochemical conditions such as $\mathrm{pH}$, temperature, moisture content, dissolved oxygen concentration, and light. Bühler et al. (2015) observed that light intensity is an essential factor in the mycelium growth and pigment production of Monascus. Indeed, monacolin K produced by ultraviolet (UV)-irradiated Monascus was three times greater than the control culture (Sun et al. 2011). Monacolin K, commercially known as lovastatin, is a potent competitive inhibitor of 3-hydroxy-3-methylglutaryl coenzyme A (HMG-CoA) reductase, inhibits cholesterol biosynthesis, and lowers blood cholesterol levels in both humans and animals. UV-mutated M. purpureus TISTR 3179 was used to produce a yellow pigment at a single $\lambda_{\max } 370 \mathrm{~nm}$ (Yongsmith et al. 2013). Huang et al. (2019) mutated Monascus spores using UV irradiation and ethyl methane sulfonate (EMS) for higher monacolin $\mathrm{K}$ and red pigment productions. The importance of light intensity in the fermentation process indicates that Monascus probably has photoreceptors that influence the physiological responses.

Rice is mainly used as a substrate for centuries (Pattanagul et al. 2007), but alternative substrates have been extensively explored. Yongsmith et al. (2013) used rice, corn, mung bean, soybean, potato, sweet potato, and cassava tubers as substrates to produce exclusively yellow pigments. Bühler et al. (2015) reported the utilization of pear juice, jackfruit seeds, ethanol, fructose, maltose, sucrose, lactose, corn syrup, grape waste, cornflour, cassava starch, and glycerol as alternative substrates for pigment production of Monascus sp. Monascus FJ46 produced MFP with a lower yield of citrinin using various carbon sources, including cereals, tuber crops, and agroindustrial residues, compared with rice flour as control $(\mathrm{Mu}$ et al. 2015). Citrinin is a mycotoxin produced by Monascus 
species, which has been a common problem in MFP production. Srianta et al. (2017) reported the use of rice, corn, and sorghum to produce MFP that has antioxidant activities. So, far, purple sweet potato and black rice have not been used as substrates for MFP. Thus, in this research, we proposed purple sweet potato (Ipomoea batatas (L.) Lam.) and black rice (Oryza sativa L.) as two new alternative substrates for MFP.

Purple sweet potato and black rice are considered functional foods because they are rich in anthocyanin, which also serves as their natural pigment (Ginting et al. 2015; Sompong et al. 2011). Anthocyanin is reported to have various biological activities, including strong antioxidant, anti-inflammatory, and antimicrobial properties (Khoo et al. 2017; Esatbeyoglu et al. 2017; Zhi et al. 2020). Black rice also contains active phytochemicals such as tocopherol, tocotrienols, oryzanols, vitamin B complex, and phenolic compounds (Jang et al. 2012). It also has phenolic-active ingredients four times higher than white rice (Thanuja and Parimalavalli 2020). Hence, the bioactive components in purple sweet potato and black rice make them potential substrates to increase the nutraceutical uses of MFP.

The application of MFP as a coloring additive provides additional advantages such as preservatives and food supplements (Srianta et al. 2014). The pigments produced by Monascus are used as food preservatives because of their antimicrobial activities. The pigments have been reported to inhibit the growth of fungi such as Aspergillus, Trichoderma, Mucor, Penicillium, and Fusarium and bacteria such as Bacillus, Pseudomonas, Escherichia, and Streptomyces (Ungureanu and Ferdes 2010). Rojsuntornkitti et al. (2010) noted that Monascus red pigment is used as a substitute for nitrite inhibited Salmonella spp., Clostridium perfringens, and Staphylococcus aureus in Thai sausage. Salmonella causes foodborne diseases because of food and water contamination. Until now, typhoid fever caused by Salmonella typhi is a global burden with 11.0-17.8 million typhoid fever illnesses occurring annually worldwide (Crump 2019). Recently, S. typhi resistances include antibiotics ampicillin, trimethoprim-sulfamethoxazole (TMP-SMX), ciprofloxacin, and ceftriaxone (Wong et al. 2019). The increasing threat of antimicrobial resistance is the reason for the search for alternative antibacterials for $S$. typhi from natural sources. Therefore, the objectives of this research were evaluating the use of purple sweet potato and black rice as new substrates for MFP production using UVirradiated $M$. purpureus and analyzing their antibacterial activity against $S$. typhi.

\section{MATERIALS AND METHODS}

\section{Procedures}

\section{Substrate preparation}

Purple sweet potato (Ipomoea batatas L.) and organic black rice (Oryza sativa L.) Hotel ${ }^{\circledR}$ were purchased from a local market, that is, Pasar Wage, Purwokerto. Individually, purple sweet potato and black rice were prepared as described by Ginting et al. (2015), with modification. The tubers of purple sweet potatoes were thinly sliced, dried at $60^{\circ} \mathrm{C}$ for $32 \mathrm{~h}$, ground, and then sieved with a 60 mesh to obtain a fine powder of purple sweet potato. Similarly, the black rice was thoroughly washed, dried at $60^{\circ} \mathrm{C}$ for $12 \mathrm{~h}$, ground, and then sieved with a 60 mesh to obtain a fine powder of black rice.

\section{Evaluation of Monascus growth pattern}

Monascus purpureus was obtained from the Indonesian Culture Collection (InaCC) LIPI Bogor. M. purpureus was cultivated in potato dextrose agar (PDA) and incubated at $30^{\circ} \mathrm{C}$ for 7 days before being used. The growth pattern of $M$. purpureus for each substrate was evaluated based on mycelial growth. The medium used was modified from Permana et al. (2004). It consisted of fine powder of purple sweet potato or black rice $(5 \%), \mathrm{KH}_{2} \mathrm{PO}_{4}(0.25 \%), \mathrm{NaNO}_{3}$ $(0.15 \%), \mathrm{MgSO}_{4} .7 \mathrm{H}_{2} \mathrm{O}(0.1 \%)$, monosodium glutamate $(0.1 \%), \mathrm{CaCl}_{2}(0.001 \%)$, and distilled water up to $100 \mathrm{~mL}$. The $\mathrm{pH}$ was adjusted to 6.0 , and the medium was sterilized at $121^{\circ} \mathrm{C}$ for $15 \mathrm{~min}$. After cooling, the medium was inoculated with $M$. purpureus and incubated at $30^{\circ} \mathrm{C}$. The mycelial growth was measured as dry weight every day for 7 days. The incubation time with the highest mycelial weight was used for inoculum preparation.

\section{UV irradiation and inoculum preparation}

M. purpureus was inoculated with PDA in a Petri dish. Aseptically, the Petri disk cover was opened, and the culture was irradiated with ultraviolet light at $\lambda 254 \mathrm{~nm}$ with exposure times of $0,2,3$, and $4 \mathrm{~min}$. The control was $M$. purpureus without UV irradiation $(0 \mathrm{~min})$. All irradiated $M$. purpureus samples were then incubated at $30^{\circ} \mathrm{C}$ for 7 days. The sterilized medium, as described earlier, was inoculated with irradiated $M$. purpureus and incubated at $30^{\circ} \mathrm{C}$ for 4 days to produce an inoculum.

\section{Solid-state fermentation}

Solid-state fermentation was performed using Completely Randomized Factorial Design with three factorials. The first factor was two types of substrate (S1 = purple sweet potato and S2 = black rice), the second factor was four lengths of UV irradiation at $\lambda 254 \mathrm{~nm}(\mathrm{R} 0=0$ $\min , \mathrm{R} 1=2 \mathrm{~min}, \mathrm{R} 2=3 \mathrm{~min}$, and $\mathrm{R} 3=4 \mathrm{~min}$ ), and the third factor was three incubation times $(\mathrm{T} 1=7$ days, $\mathrm{T} 2=$ 14 days, and $\mathrm{T} 3=21$ days). The choice of incubation times followed Yongsmith et al. (2013) with modification. Each treatment was repeated two times, so there were 48 experimental units. The parameters measured were the yield of the Monascus fermented products (MFPs) and the absorbance of the ethanol extracts of MFP at $\lambda 390$ and $\lambda 500 \mathrm{~nm}$ for pigment evaluation.

$100 \mathrm{~g}$ of purple sweet potato (S1) or black rice powder (S2) was sterilized at $121^{\circ} \mathrm{C}$ for $15 \mathrm{~min}$. After cooling, each substrate was inoculated with $2 \%$ inoculum. The mixture was stirred aseptically and then closed tightly with sterilized parchment paper. The mixture was incubated at $30^{\circ} \mathrm{C}$ with three incubation times (T1, T2, and T3). After each incubation time, all MFPs were dried in an oven at 
$60^{\circ} \mathrm{C}$ to yield irradiated MFP types, which were MFPpurple sweet potato and MFP-black rice.

$0.05 \mathrm{~g}$ of MFP products were extracted with $10 \mathrm{~mL}$ of $95 \%$ ethanol. The mixture was centrifuged, and the filtrate obtained was measured with UV-Vis spectrophotometry at $\lambda 390 \mathrm{~nm}$ for the yellow pigment and $\lambda 500 \mathrm{~nm}$ for the red pigment (Kasim et al. 2005). The MFP product with the highest absorbance was evaluated for antibacterial activity against Salmonella typhi.

\section{Evaluation of antibacterial activity}

The MFP product with the highest absorbance was extracted with $95 \%$ ethanol with a ratio of $1: 5(\mathrm{w} / \mathrm{v})$ by maceration. After $3 \times 24$ h of macerations, each mixture was filtered, and the filtrate obtained was evaporated to give the ethanol extract. The antibacterial activity of the ethanol extract against Salmonella typhi was evaluated by disk diffusion or Kirby-Bauer method (Hudzicki 2009). S. typhi was from the Microbiology Laboratory, Faculty of Biology, Universitas Jenderal Soedirman, Purwokerto. S. typhi on nutrient agar slant was serially diluted with sterile $0.9 \% \mathrm{NaCl}$ into $10^{-5}$ dilution. $100 \mu \mathrm{L}$ of $10^{-5}$ suspension of $\mathrm{S}$. typhi was uniformly spread over the NA medium and incubated $37^{\circ} \mathrm{C}$ overnight. Paper disks $(\varnothing 6 \mathrm{~mm}$, thickness of $0.5 \mathrm{~mm}$ ) were impregnated with $15 \mu \mathrm{L}$ of four concentrations $(0.05,0.10,0.15$, and $0.20 \mathrm{~g} / \mathrm{mL})$ of ethanol extracts. Then, each disk was put on NA plates inoculated with $S$. typhi and incubated at $37^{\circ} \mathrm{C}$ for $24 \mathrm{~h}$. The positive control was $5 \%(\mathrm{w} / \mathrm{v})$ of chloramphenicol, and the negative one was a sterile aqueous solution. The inhibition zone of each extract was calculated based on the diameter inhibition zone minus the diameter of the paper disk used.

\section{Analysis of ethanol extract}

The ethanol extract with the highest antibacterial activity was analyzed using thin-layer chromatography (TLC), followed by bioautography. The ethanol extract was spotted on the TLC sheet (Silica gel $60-$ F254 nm) and eluted with n-butanol: acetic acid: water (5:1:4). After elution, each TLC was sprayed with the following reagents: $1 \%$ ethanolic solution of $\mathrm{AlCl}_{3}$ for flavonoid, $p$ anisaldehyde-sulfuric acid for terpenoid, $1 \% \mathrm{FeCl}_{3}$ for tannin, Dragendorff reagent for alkaloid, and LiebermannBurchard reagent for saponins. All TLCs were observed under UV light at $\lambda 365 \mathrm{~nm}$ for color changes, and its $R_{f}$ value was calculated (Waldi 1965). Each separated spot from TLC was carefully scraped with a sterile spatula and then impregnated directly on the NA inoculated with $S$. typhi for bioautography analysis. The plates were incubated at $37^{\circ} \mathrm{C}$ for $24 \mathrm{~h}$. The inhibition zone observed was calculated and compared to the TLC results (Nostro et al. 2000).

\section{Data analysis}

The data from solid-state fermentation were analyzed using analysis of variance. The results that showed significant diversity were further analyzed using Duncan's multiple range test (DMRT) with a $95 \%$ confidence level $(\alpha=0.05)$. The lowest concentration of ethanol extracts capable of inhibiting $S$. typhi was considered the minimum inhibitory concentration (MIC).

\section{RESULTS AND DISCUSSION}

\section{The morphology of $M$. purpureus}

The morphology development of $M$. purpureus cultivated on PDA was observed for 7 days at $27^{\circ} \mathrm{C}-32^{\circ} \mathrm{C}$. The culture rapidly grew and spread on the surface of the media. The colony has a diameter of $20-30 \mathrm{~mm}$, the texture was wooly, and the surface was flocculent superficial. In the early stage, the color of the mycelium was white. It rapidly turned into pink, subsequently into yellow-orange, and finally became crimson red as the colony ages (Figure 1). The red pigment was observed both in the mycelium and diffused pigment in the media.

Monascus purpureus showed different growth characteristics because of UV irradiation at $\lambda 254 \mathrm{~nm}$. The colony changed in size, shape, and color of the mycelium. The colony's size was reduced to $2-6 \mathrm{~mm}$ in diameter, the shape became round, and the color of the mycelium was white to reddish-orange (Figure 2). The growth of $M$. purpureus after $2 \mathrm{~min}$ of $\mathrm{UV}$ irradiation was better compared to others.

\section{Analysis of growth pattern}

The growth of $M$. purpureus in liquid medium was evaluated as the increment in mycelium weight (g) during incubation time (d). The research results showed that the growth curve of $M$. purpureus on both purple sweet potato and black rice substrates followed the growth pattern of fungi in general. M. purpureus grew quickly up to the fourth day of cultivation and slowed down after that. The highest mycelium weight (1.86 g) using purple sweet potato substrate was achieved on the fourth day, and the black rice substrate has the highest mycelium weight $(2.32$ g) after the fourth day of incubation. Thus, the inoculum of $M$. purpureus was prepared by the cultivation of spores in a liquid medium for 4 days. Mycelium weight clearly indicated that the growth of $M$. purpureus was better in black rice than in purple sweet potato as a substrate (Figure 3 ). Besides, purple sweet potato formed sticky clumps, which might hamper the dispersal of oxygen and nutrients for the effective growth of $M$. purpureus.

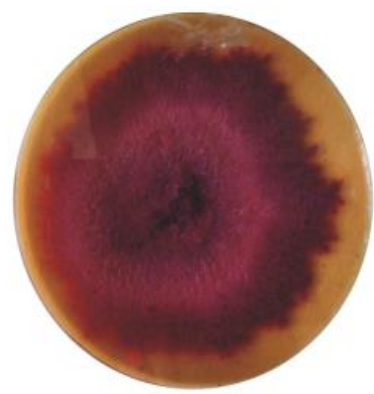

A

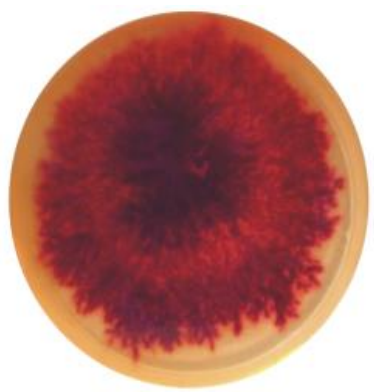

B
Figure 1. The colony of M. purpureus. A. View from the top, B. View from the bottom 


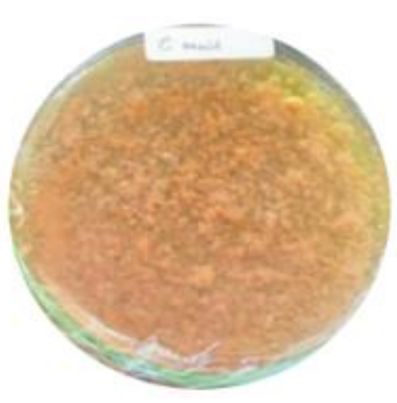

$\mathbf{A}$

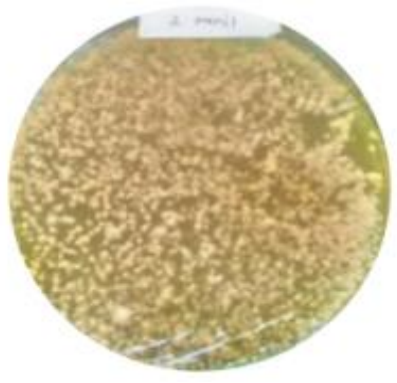

B

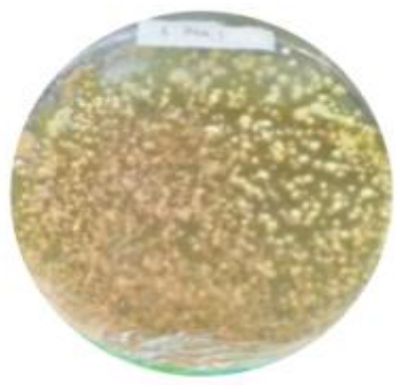

C

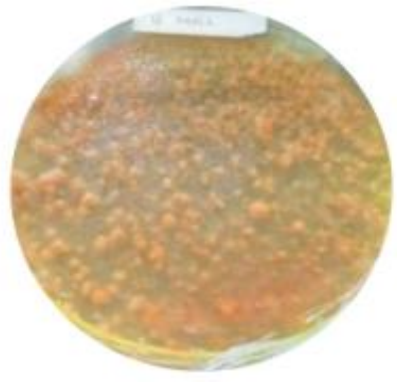

D

Figure 2. The colony of M. purpureus after UV irradiation for: A. 0, B. 2, C. 3, D. $4 \mathrm{~min}$

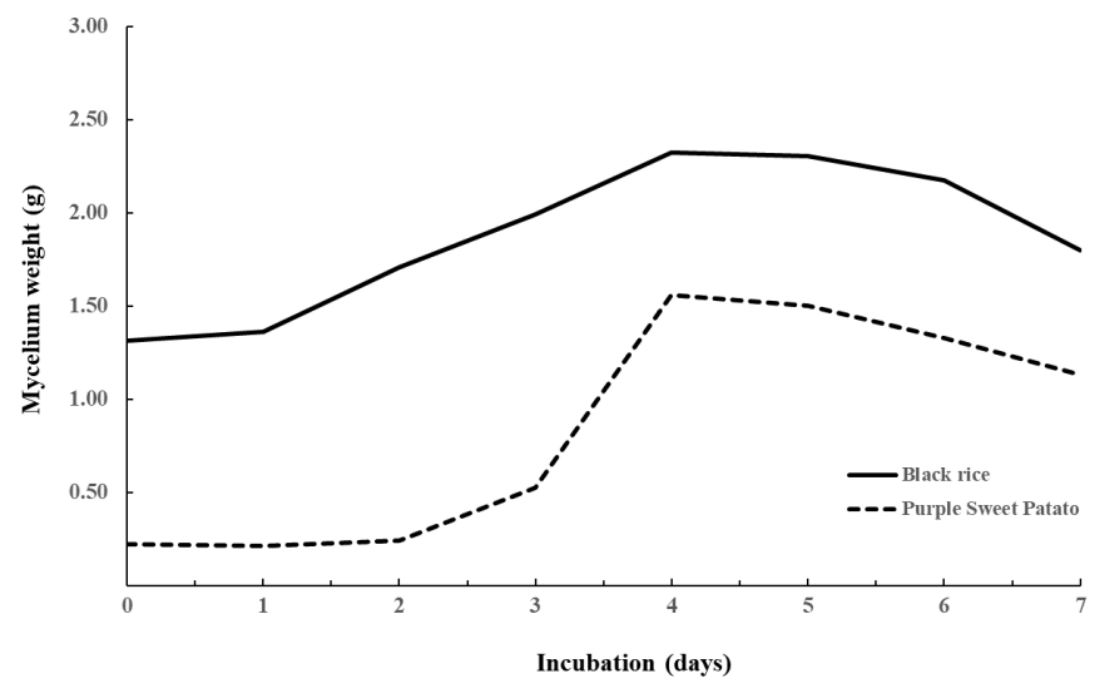

Figure 3. The growth curve of M. purpureus on purple sweet potato and black rice substrates

\section{Monascus fermented product (MFP)}

Fermentation processes were conducted for 21 days with an interval of 7 days. MFP-purple sweet potato was sticky solid and reddish-black, had a sweet odor, and caramelized, whereas MFP-black rice was sticky and reddish-black and had a grainy form. The yield of MFP-purple sweet potato varied from $5.97 \%$ to $26.48 \%$. The highest yield $(26.48 \%)$ was obtained from fermentation with UV-irradiated $M$. purpureus for $3 \mathrm{~min}$ and incubation for 21 days. The yield of MFP-black rice varied from $42.47 \%$ to $51.88 \%$. The highest yield (51.88\%) was obtained with UV-irradiated $M$. purpureus for $2 \mathrm{~min}$ and incubation for $21 \mathrm{~d}$. The overall results indicated that MFP-black rice had a higher yield than MFP-purple sweet potato (Figure 4).

The absorbance values of the ethanol extract from MFP-purple sweet potato and MFP-black rice are shown in Table 1 and Table 2, respectively. The fermentation process with a longer incubation time produced a higher absorbance value. These results applied for both MFPpurple sweet potato and MFP-black rice. The absorbance of the yellow pigment at $\lambda 390 \mathrm{~nm}$ was varied from $0.17 \pm$ 0.01 to $3.90 \pm 0.12$, whereas the absorbance of the red pigment at $\lambda 500 \mathrm{~nm}$ was varied from $0.03 \pm 0.00$ to $3.98 \pm$ 0.02 . The highest absorbance of both pigments in MFPpurple sweet potato was obtained from UV-irradiated $M$. purpureus for 3 min (MFP3-purple sweet potato), whereas that in MFP-black rice was obtained from UV-irradiated M. purpureus for 2 min (MFP2-black rice). Both fermentations occurred in 21 days. The result of the variance analysis showed that the interaction of substrates, length of UV irradiation, and incubation time were significantly different at a $95 \%$ confidence level $(p>0.05)$. This result indicated that the type of substrate, length of UV irradiation, and fermentation time affect MFP production.

\section{Antibacterial activity of ethanol extracts}

Ethanol extracts from both MFP3-purple sweet potato and MFP2-black rice showed antibacterial activity toward $S$. typhi with inhibition zones of 1.0 and $1.5 \mathrm{~mm}$, respectively. The minimum inhibition concentrations (MICs) of ethanol extracts were $0.2 \mathrm{~g} / \mathrm{L}$ for MFP3-purple sweet potato and $0.15 \mathrm{~g} / \mathrm{mL}$ for MFP2-black rice. This finding suggested the possible use of MFP3-purple sweet potato and MFP2-black rice as functional food ingredients not only for food colorants but also for the prevention of $S$. typhi infection. The T-test analysis result at a 95\% confidence level indicated the difference in the antibacterial activities of MFP3-purple sweet potato and MFP2-black rice to $S$. typhi. Correlation test (r) between concentrations of fermented substrates showed that MFP2black rice had a better antibacterial activity to $S$. typhi than MFP3-purple sweet potato. 
Since MFP2-black rice has the highest antibacterial activity, its ethanol extract was used for TLC and bioautography. The TLC results gave three spots with $\mathrm{R}_{\mathrm{f}}$ values of $0.23,0.85$, and 0.96 . The results from spray reagents indicated the presence of saponin (first spot), flavonoid (second spot), and an alkaloid (third spot) compounds. Each spot was scraped carefully and subjected to media inoculated with $S$. typhi for bioautography analysis using an aqueous solution as the negative control. After incubation, the first and second spots showed inhibition against $S$. typhi growth, with inhibition zones of 14.7 and $19.0 \mathrm{~mm}$, respectively (Figure 5). These results suggested that MFP2-black rice contained saponin and flavonoid, which have antibacterial activity toward S. typhi.
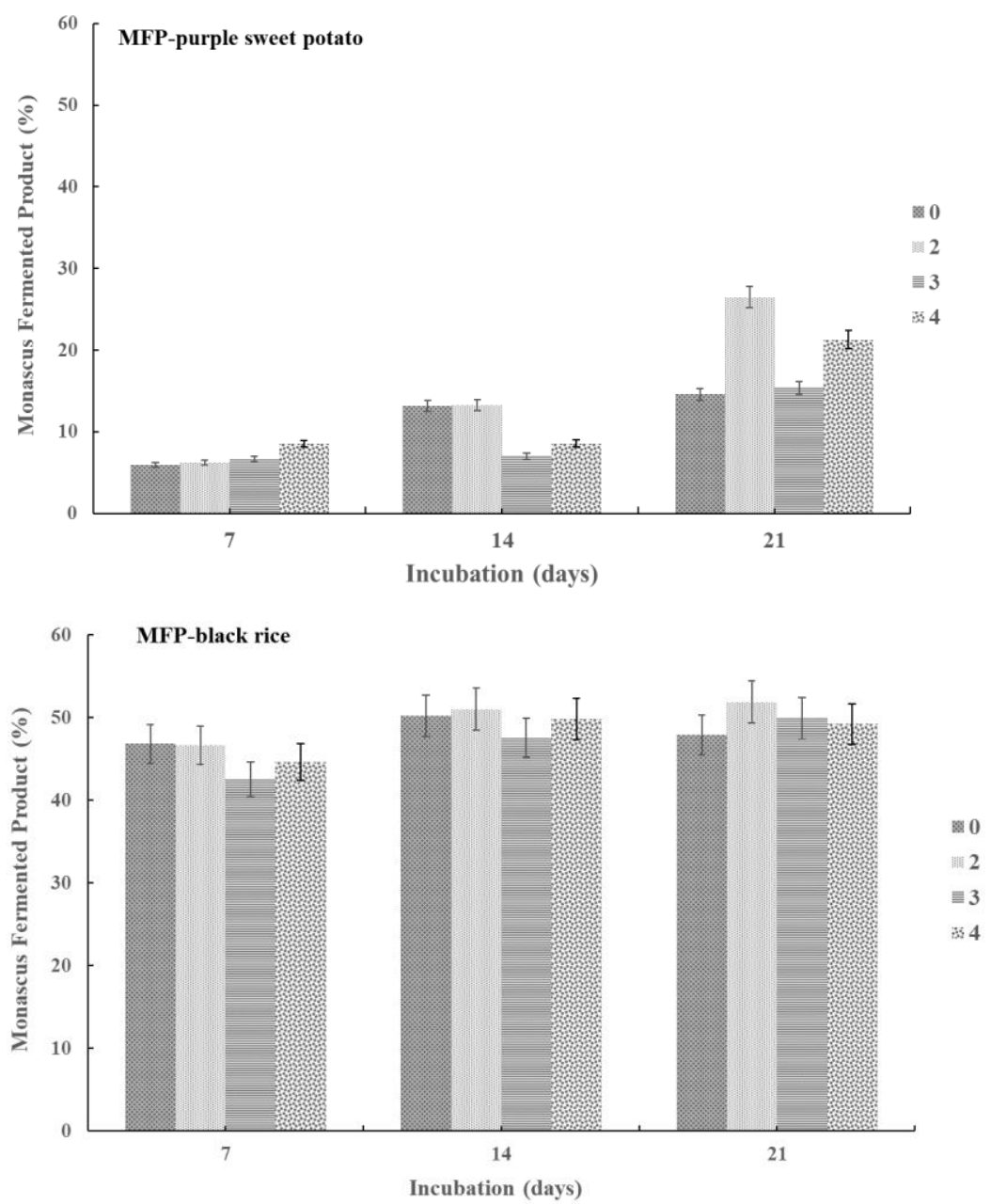

Figure 4. Monascus fermented product from purple sweet potato and black rice substrates

Table 1. The absorbance of ethanol extracts from MFP-purple sweet potato

\begin{tabular}{lcccccc}
\hline \multirow{2}{*}{ Sample } & \multicolumn{3}{c}{ Absorbance $\boldsymbol{K}_{\mathbf{3 9 0 n m}}$} & \multicolumn{3}{c}{ Absorbance $\boldsymbol{\kappa}_{\mathbf{5 0 0 n m}}$} \\
\cline { 2 - 7 } & $\mathbf{7 ~ d a y s}$ & $\mathbf{1 4}$ days & 21 days & 7 days & 14 days & 21 days \\
\hline 0 min & $0.30 \pm 0.20$ & $0.78 \pm 0.00$ & $3.59 \pm 0.08$ & $0.12 \pm 0.05$ & $0.53 \pm 0.00$ & $2.26 \pm 0.01$ \\
2 min & $0.42 \pm 0.00$ & $1.78 \pm 0.00$ & $3.78 \pm 0.26$ & $0.19 \pm 0.00$ & $1.52 \pm 0.00$ & $3.22 \pm 0.01$ \\
3 min & $0.17 \pm 0.01$ & $0.82 \pm 0.00$ & $3.90 \pm 0.12$ & $0.03 \pm 0.00$ & $0.56 \pm 0.00$ & $3.98 \pm 0.03$ \\
4 min & $0.08 \pm 0.05$ & $0.53 \pm 0.00$ & $2.37 \pm 0.00$ & $0.03 \pm 0.00$ & $0.30 \pm 0.00$ & $1.55 \pm 0.01$ \\
\hline
\end{tabular}

Table 2. The absorbance of ethanol extracts from MFP-black rice

\begin{tabular}{lcccccc}
\hline \multirow{2}{*}{ Sample } & \multicolumn{3}{c}{ Absorbance $\boldsymbol{K}_{\mathbf{3 9 0} \mathbf{n m}}$} & \multicolumn{3}{c}{ Absorbance $\boldsymbol{K}_{\mathbf{5 0 0 n m}}$} \\
\cline { 2 - 7 } & $\mathbf{7 ~ d a y s}$ & $\mathbf{1 4}$ days & $\mathbf{2 1}$ days & $\mathbf{7 ~ d a y s}$ & $\mathbf{1 4}$ days & $\mathbf{2 1 ~ d a y s}$ \\
\hline 0 min & $0.87 \pm 0.01$ & $0.43 \pm 0.00$ & $3.65 \pm 0.25$ & $0.55 \pm 0.01$ & $0.28 \pm 0.01$ & $3.60 \pm 0.00$ \\
$2 \mathrm{~min}$ & $0.78 \pm 0.00$ & $2.78 \pm 0.02$ & $3.85 \pm 0.17$ & $0.45 \pm 0.00$ & $2.05 \pm 0.00$ & $3.98 \pm 0.02$ \\
3 min & $0.74 \pm 0.01$ & $2.36 \pm 0.01$ & $3.74 \pm 0.30$ & $0.44 \pm 0.00$ & $2.09 \pm 0.01$ & $3.48 \pm 0.01$ \\
$4 \mathrm{~min}$ & $1.06 \pm 0.01$ & $1.20 \pm 0.01$ & $3.83 \pm 0.06$ & $0.67 \pm 0.00$ & $1.13 \pm 0.00$ & $3.60 \pm 0.00$ \\
\hline
\end{tabular}



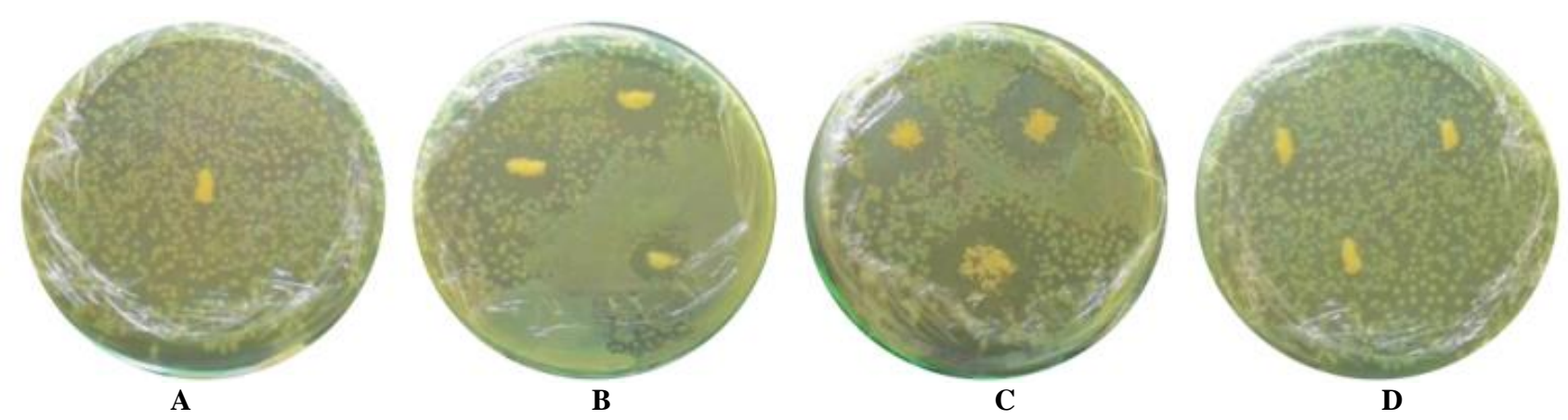

Figure 5. Bioautography results of three TLC spots from the ethanol extract of MFP2-black rice. A. The negative control, B. First spot, C. Second spot, D. Third spot

\section{Discussion}

The growth of $M$. purpureus was affected by UV irradiation. Bühler et al. (2015) stated that the average radial growth of $M$. purpureus was between 2.3 and 3.1 $\mathrm{mm}$. He observed a decrease in the radial growth rate of Monascus ruber exposed to direct illumination. The radial growth rate was $1.50 \mathrm{~mm}$ in darkness, whereas it was reduced to $0.59 \mathrm{~mm}$ with direct illumination.

Various preparations of inoculum have been reported. Inoculum for lovastatin production was prepared with the inoculation of $M$. purpureus spore in rice substrate and incubated for 14 days (Kasim et al. 2005). Inoculum from various cereals, tuber crops, and agro-industrial residues was prepared by cultivating the spore of Monascus strain FJ46 for $24 \mathrm{~h}$ in a rotary shaker incubator (Mu et al. 2015). The inoculum of $M$. ruber CCT3802 was obtained by the germination of $M$. ruber spores for $60 \mathrm{~h}$ (Bühler et al. 2015). M. purpureus starter for MFP with antioxidant activity was prepared by inoculating M. purpureus M9 and incubated for 7 days (Srianta et al. 2017). The inoculum preparation varies, possibly because of the different intended utilization.

MFP-purple sweet potato gave lower yields than MFPblack rice. The difference in yield might be due to the variation in carbohydrate content. Black rice contains $74.09 \%$ to $75.71 \%$ of total carbohydrates (Sompong et al. 2011), whereas the purple sweet potato contains $22.64 \%$ of carbohydrates (Ginting et al. 2015). During fermentation, M. purpureus consumes starchy substrates as a source of energy for the growth and developmental needs of secondary metabolites. It produces glucoamylase and $\alpha$ amylase enzymes, the key enzymes for starch hydrolysis (Yoshizaki et al. 2010). Thus, the difference in carbohydrate content apparently results in a different fermentation product yield.

Monascus produces pigments at various incubation times. M. purpureus M9 produced MFP with antioxidant activity after 14 days of incubation (Srianta et al. 2017). Mutant Monascus sp. TISTR 3179 rapidly produced yellow pigments after 5 days of cultivation using rice, corn, mung bean, soybean, potato, sweet potato, and cassava tubers as substrates (Yongsmith et al. 2013). Huang et al. (2019) observed that the cell growth of mutant Monascus U-2 increased rapidly and reached its maximum at the $10^{\text {th }}-11^{\text {th }}$ day of incubation. During the exponential phase of cell growth, monacolin $\mathrm{K}$ was produced and reached its maximum during the $17^{\text {th }}-18^{\text {th }}$ day of incubation. These observations indicated that Monascus produced secondary metabolites during the stationary phase of cell growth. However, a shorter incubation time for monacolin $\mathrm{K}$ production was reported by Sun et al. (2011). Monacolin K level reached the highest on day 13 when Sporobolomyces huaxiensis was introduced as a fungal elicitor in the fermentation system.

In this research, $M$. purpureus converted the substrate into primary metabolite products for cell growth and had sufficient time to form pigments as secondary metabolites during stationary phases from 7 to 21 days of incubation. UV irradiation toward M. purpureus increased the intensity of the pigment until it reached a certain exposure time. Longer exposure to UV irradiation decreased the intensity of pigments, which might alter the microbial ability to produce pigments. MFPs with the highest absorbance values, which were MFP3-purple sweet potato and MFP2black rice, were further analyzed for antibacterial activity.

Monascus pigments produced by $M$. ruber CCT 3802, M. purpureus, M. purpureus N11S, and Monascus M3428 showed antimicrobial activity against Escherichia coli, Salmonella enteritidis, B. subtilis, S. aureus, and yeast, respectively. These antimicrobial activities of Monascus pigments indicate their potential as food preservatives (Kim and Ku 2018). Christiana (2016) mentioned that the antimicrobial activities of Monascus pigments vary with the type of pigment. Ungureanu and Ferdes (2010) reported that the red pigment from red yeast rice inhibited the growth of Bacillus subtilis, Pseudomonas aeruginosa, and Streptomyces albus. The bacteriostatic effects suggested the preservative value of the Monascus pigment. Rojsuntornkitti et al. (2010) used M. purpureus TISTR 3080 to produce Chinese red broken rice with antibacterial activity against $C$. perfringens, Salmonella spp., and $S$. aureus. The yellow pigment produced by mutant Monascus sp. TISTR 3642 was useful for the protection of food products, such as fresh Chinese noodles, or non-food products, such as cosmetics (Yongsmith et al. 2013).

Purple sweet potato and black rice served as potential substrates for MFP using UV-irradiated M. purpureus for 3 and $2 \mathrm{~min}$, respectively. Solid-state fermentation was 
carried out for 21 days to obtain the highest yield. The ethanol extracts from both MFP-purple sweet potato and MFP-black rice showed antibacterial activities against $S$. typhi. Further studies on the elucidation of the bioactive compounds from MFP-purple sweet potato and MFPblack rice will be considered for a better understanding of their pharmaceutical benefits.

\section{ACKNOWLEDGEMENTS}

The authors would like to acknowledge the Head of the Bureau of Planning and Foreign Cooperation under the Ministry of Education and Culture of Republic Indonesia for the Excellent Scholarship. All authors have read and approved the final manuscript. The authors declare that there are no conflicts of interest.

\section{REFERENCES}

Bühler RMM, Müller BL, Moritz DE, Vendruscolo F, de Oliveira D, Ninow JL. 2015. Influence of light intensity on growth and pigment production by Monascus ruber in submerged fermentation. Appl Biochem Biotechnol 176 (5): 1277-1289.

Christiana NO. 2016. Production of food colorants by filamentous fungi. Afr J Microbiol Res 10 (26): 960-971.

Crump JA. 2019. Progress in typhoid fever epidemiology. Clin Infect Dis 68 (Suppl1): S4-S9.

Esatbeyoglu T, Rodríguez-Werner M, Schlösser A, Winterhalter P, Rimbach G. 2017. Fractionation, enzyme inhibitory, and cellular antioxidant activity of bioactive from purple sweet potato (Ipomoea batatas). Food Chem 221: 447-456.

Ginting E, Utomo JS., Yulifianti R, Jusuf M. 2015. Potensi ubi jalar ungu sebagai pangan fungsional. Iptek Tanaman Pangan 6 (1): 116-138. [Indonesian]

Huang CF, Shen SM, Chen WT, Chen CC. 2019. The effects of mutation and temperature variation on monacolin $\mathrm{K}$ production by Monascus sp. and relative statistical parameter analysis of monacolin $\mathrm{K}$ production. Phytochem Lett 32: 143-150.

Hudzicki J. 2009. Kirby-Bauer Disk Diffusion Susceptibility Test Protocol. Retrieved on July 20, 2019 from the website: https://www.asmscience.org/content/education/protocol/protocol.318 9\#header.

Jang HH, Park MY, Kim HW, Lee YM, Hwang KA, Park JH, Park DS, Kwon O. 2012. Black rice (Oryza sativa L.) extract attenuates hepatic steatosis in C57BL/6 J mice fed a high-fat diet via fatty acid oxidation. Nutr Metab 9 (27): 1-11.

Kasim E, Astuti S, Nurhidayat N. 2005. Karakterisasi pigmen dan kadar lovastatin beberapa isolat Monascus purpureus. Biodiversitas 6 (4): 245-247. [Indonesian]

Khoo HE, Azlan A, Tang ST, Lim SM. 2017. Anthocyanidins and anthocyanins: colored pigments as food, pharmaceutical ingredients, and the potential health benefits. Food Nutr Res 61 (1361779): 1-18.
Kim D, Ku S. 2018. Beneficial effects of Monascus sp. KCCM 10093 pigments and derivatives: A mini-review. Molecules 23 (1): 1-15.

Mu H, Huang L, Ding X, Zhao S. 2015. Influence of different substrates on the production of pigments and citrinin by Monascus FJ46. In: Zhang T, Nakajima M (eds) Advances in Applied Biotechnology. Lecture Notes in Electrical Engineering, Springer, Berlin, Heidelberg.

Nostro A, Germano MP, D'angelo V, Marino A, Cannatelli MA. 2000. Extraction methods and bioautography for evaluation of medicinal plant antimicrobial activity. Lett Appl Microbiol 30 (5): 379-384.

Pattanagul P, Pinthong R, Phianmongkhol A, Leksawasdi N. 2007. Review of angkak production (Monascus purpureus). Chiang Mai J Sci 34 (3): 319-328.

Permana DR, Marzuki S, and Tisnadjaja D. 2004. The analysis of the quality of red fermented rice (RFR) product with Monascus purpureus 3090. Biodiversitas 5 (1): 7-12. [Indonesian]

Rojsuntornkitti K, Jittrepotch N, Kongbangkerd T, Kraboun K. 2010. Substitution of nitrite by Chinese red broken rice powder in Thai traditional fermented pork sausage (Nham). Intl Food Res J 17 (1): 153-161.

Sompong R, Siebenhandl-Ehn S, Linsberger-Martin G, and Berghofer E. 2011. Physicochemical and antioxidative properties of red and black rice varieties from Thailand, China and Sri Lanka. Food Chem 124 (1): $132-140$

Srianta I, Ristiarini S, Nugerahani I, Sen SK, Zhang BB, Xu GR, Blanc PJ. 2014. Recent research and development of Monascus fermentation products. Intl Food Res J 21 (1): 1-12.

Srianta I, Zubaidah E, Estiasih T, Iuchi Y, Yamada M. 2017. Antioxidant activity of pigments derived from Monascus purpureus-fermented rice, corn, and sorghum. Intl Food Res J 24 (3): 1186-1191.

Sun JL, Zou X, Liu AY, Xiao TF. 2011. Elevated yield of monacolin K in Monascus purpureus by fungal elicitor and mutagenesis of UV and LiCl. Biol Res 44 (4): 377-382.

Thanuja B, Parimalavalli R. 2020. Comparison of antioxidant compounds and antioxidant activity of native and dual modified rice flour. Int $\mathbf{J}$ Pharm Sci Res 11 (3): 1203-1209.

Ungureanu C, Ferdes M. 2010. Antibacterial and antifungal activity of red rice obtained from Monascus purpureus. Chem Eng Trans 20: 223228.

Waldi D. 1965. Spray Reagents for Thin-Layer Chromatography. ThinLayer Chromatogr 8: 483-502.

Wong W, Rawahi HAl, Patel S, Yau Y, Eshaghi A, Zittermann S, Tattum L, Morris SK. 2019. The first Canadian pediatric case of extensively drug-resistant Salmonella typhi originating from an outbreak in Pakistan and its implication for empiric antimicrobial choices. IDCases 15: e00492. DOI: 10.1016/j.idcr.2019.e00492.

Yongsmith B, Thongpradis P, Klinsupa W, Chantrapornchai W, Haruthaithanasan V. 2013. Fermentation and quality of yellow pigments from golden brown rice solid culture by a selected Monascus mutant. Appl Microbiol Biotechnol 97 (20): 8895-8902.

Yoshizaki Y, Susuki T, Takamine K, Tamaki H, Ito K, Sameshima Y. 2010. Characterization of glucoamylase and $\alpha$-amylase from Monascus anka: Enhanced production of $\alpha$-amylase in red koji. J Biosci Bioeng 110 (6): 670-674.

Zhi Q, Lei L, Li F, Zhao J, Yin R, Ming J. 2020. The anthocyanin extracts from purple-fleshed sweet potato exhibited anti-photoaging effects on ultraviolent B-irradiated BALB/c-nu mouse skin. J Funct Foods 64: 103640 . 